Original Article

\title{
Effect of aerobic exercises versus laser acupuncture in treatment of postmenopausal hot flushes: a randomized controlled trial
}

\author{
Eman Abdelfatah Mohamed Elhosary, PhD'1), Mahmoud Mohamed Ewidea, PhD $^{2)}$, \\ Hamada Ahmed Hamada Ahmed, PhD ${ }^{3)^{*}}$, Ayman El Khatib, PhD ${ }^{4}$ \\ 1) Department of Physical Therapy for Women's Health, Faculty of Physical Therapy, Kafrelsheikh University, Egypt \\ 2) Department of Basic Science, Faculty of Physical Therapy, Kafrelsheikh University, Egypt \\ 3) Department of Biomechanics, Faculty of Physical Therapy, Cairo University: Giza, Egypt \\ 4) Department of Physical Therapy, Faculty of Health Sciences, Beirut Arab University, Lebanon
}

\begin{abstract}
Purpose] To compare the effect of aerobic exercises versus laser acupuncture in treatment of postmenopausal hot flushes. [Subjects and Methods] This study was designed as single blind randomized controlled trial. A total of 48 postmenopausal women complained of hot flushes. Their ages ranged between 45 to 55 years and were randomly assigned into 2 equal groups: group (A), which received an aerobic exercises, and group (B), which received laser acupuncture. Both groups recieved 3 sessions per week for two months. The level of follicular stimulating hormone, lutelizing hormone, and hot flushes dairy card were assessed the severity of hot flahes before and after treatment program. [Results] There were Significant reduction in FSH, LH, and menopausal daily hot flush scale in group A compared with group B at the post treatment. [Conclusion] Eight week program of an aerobic exercises yields improvement in FSH, LH, and decrease in severity of hot flushes assessed by hot flush dairy card than laser acupuncture in the treatment of postmenopausal hot flashes.

Key words: Hot flushes, Laser acupuncture, Aerobic exercises
\end{abstract}

(This article was submitted Aug. 28, 2017, and was accepted Nov. 29, 2017)

\section{INTRODUCTION}

Menopause is defined as end of menstruation and fertility diagnosed after 12 months of amenorrhea resulting from permeant cessation of ovarian function, the last of life after menpouse tearmed as postmenpoausl period in female life ${ }^{1)}$. The mean age of the menopause in Egyptian females is $46.7^{1)}$. The premenopausal stage in which there is a change in ovarian function begin before the final menses by several years, some symptom begin before menopausal stage and persist for up to 5 years in post-menopausal period. These symptoms affect cardiovascular system, musculoskeletal system, nervous system and produce vasomotor changes and metabolic disturbances ${ }^{2}$. Some women experience no symptoms at all, other than the cessation of the menses. Hot flushes and night sweats are the most common symptoms of menopause, occur in about $80 \%$ of the menopausal females, hot flushes can lead to insomnia, irritability, fatigue, and mood swings ${ }^{3}$.

Hot flushes defined as transient, recurrent periods of heat sensation and redness, often associated with sweats, increase in skin temperature, the most affected areas of the face, neck, head or breast these symptom may result from decline in estrogen concentration and high gonadotrophin levels ${ }^{4,5}$. Hormone replacement therapy (HRT) is widely used as a medical treatment for alleviating menopausal symptoms, but many women report adverse side effects when taking HRT, common side effects include breast tenderness, bloating, bleeding and breast cancer in some cases ${ }^{6}$. Non-pharmaceutical treatment as exercises, acupuncture, reflexology are progressively used to treat menopausal symptom as hot flushes insomnia, psychological upset. They may be perceived as natural and safe methods of treatment than medications ${ }^{7)}$. Aerobic exercise has been used in man-

*Corresponding author. Hamada Ahmed Hamada Ahmed (E-mail: Hamada.ahmed@pt.cu.edu.eg)

(C2018 The Society of Physical Therapy Science. Published by IPEC Inc.

(c) (1) $\odot$ This is an open-access article distributed under the terms of the Creative Commons Attribution Non-Commercial No DerivaCC BY NC ND tives (by-nc-nd) License. (CC-BY-NC-ND 4.0: https://creativecommons.org/licenses/by-nc-nd/4.0/) 
agement of a variety of medical disorders associated with menopausal women as hyperlipidemia, osteoarthritis, fibromyalgia, and diabetes, hot flushes and depression ${ }^{8}$, continues aerobic activites improved female's quality of life, decrease sensation of fatigue, less incidence of depression and irritability ${ }^{9}$.

Laser acupuncture is form of phototherapy considered as a simple noninvasive alternative to metal needles for the stimulation of acupuncture or musculoskeletal trigger points and recommended as a treatment method of menopausal symptoms and other gynecological conditions ${ }^{10)}$. It is commonly termed "Laser Acupuncture" to distinguish it from the wider therapeutic applications of laser ${ }^{11)}$ No study has yet compared between the effect of aerobic exercise and laser acupuncture in treatment of hot flushes. Thus, the aim of this study was to investigate which modality gives better results in treating hot flushes.

\section{SUBJECTS AND METHODS}

The study was designed as a prospective, randomized, single-blind, pre-post-test, controlled trial. A convenient sample of 48 postmenopausal females were recruited from Kafr el sheikh university hospital, outpatient clinic of obstetrics and gynaecology department. They were enrolled and assessed for their eligibility to participate in the study. Their age ranged from 45 to 55 years. After a brief orientation session about the nature of the study and the tasks to be accomplished, they were randomly assigned into two equal groups (group (A) and group (B)) by a blinded and an independent research assistant who opened sealed envelopes that contained a computer generated randomization card. No subjects dropped out of the study after randomization. Written informed consent was obtained from all participants before the baseline evaluation. Ethical approval was obtained from the institutional review board at Faculty of physical therapy, Cairo University before study commencement with number P.T.REC/012/001650. The study followed the Guidelines of Declaration of Helsinki on conduction of human research. The study was conducted between October 2015 and December 2016. The inclusion criteria were participants age ranged from 45 to 55 years old; complain from recurrent hot flashes, and had body mass index (BMI) ranged from 30 to $32 \mathrm{~kg} / \mathrm{m}^{2}$. Participants were excluded if they had diabetes, hypertension, cardiac diseases and no history of neurological or musculoskeletal disorder. Participants were randomly assigned into 2 equal groups, groups (A) received aerobic exercises 3 sessions per week for two months. Each session were 40 mins walking, (divided into 10 mins warming up, 20 mins exercise and 10 mins cooling down). Exercise was at 60-70\% HR max as HR max=220 - Age ${ }^{12)}$. Group (B) received laser acupuncture on of laser acupoints The patient was in a comfortable, supine position. After the skin was routinely disinfected and the acupoints were carefully localized, (Sanyinjiao (sp6), Hegu (LI.4), Quchi (LI.11), Fengchi (GB.20.), Guanyuan (CV 4.) and Fuliu (KI7)) of both sides, Infrared laser diode will be applied 90 sec/each point, with wave length $904 \mathrm{~nm}$ and power output 5 mill watts. Three sessions per week for two months ${ }^{13)}$. The level of Follicular stimulating hormone (FSH) and luteinizing hormone ( $\mathrm{LH})$ were measured by lab analysis of blood as primary outcomes before and after treatment in both groups. As well as, the severity of hot flushes recorded by patient in hot flushes dairy card and calculated as the mean of three days record before treatment and three days record after the end of the treatment period. The responses were subjectively assessded and classified into: None (disappearance of hot flushes): no symptoms remain after treatment and no recurrent by the following up visit, mild (very few hot flushes): symptoms have improved, but a few mild hot flushes each lasting less than one minute, moderate: symptoms are largely alleviated but the patient may still have frequent attaches hot flushes each lasting 1-4 minutes, and severe: the symptoms remain unchanged ${ }^{14)}$.

Data analysis was performed using (SPSS, Inc. Chicago, IL, USA) program version 22 for Windows. The sample size (48 patients) was calculated to yield an $90 \%$ power, effect size $=0.827$ calculated from unpublished pilot study on 12 participants (6 in each group) considering FSH and LH as a primary outcomes and $\alpha=0.05$. Prior to final analysis, data were screened for normality assumption and presence of extreme scores. This exploration was done as a pre-requisite for parametric calculation of the analysis of differences and of relationship measures. Normality test of data using Shapiro-Wilk test was used, this ensures that the data is normally distributed for FSH and LH and not normally distributed for menopausal daily hot flush scale (MDHS). Therefore, $2 \times 2$ Mixed design MANOVA was used to compare the FSH and LH at different tested groups and training periods. Also, non-parametric statistical tests in the form of Wilcoxon Signed Rank tests was used to compare MDHS between pre and post treatment for each group and Mann-Whitney U test was used to compare it between both groups at both measuring periods. The alpha level was set at 0.05 .

\section{RESULTS}

There were no statistically significant differences $(p>0.05)$ between subjects in both groups concerning age, weight, height, and BMI. There were no statistically significant differences $(\mathrm{p}>0.05)$ between subjects in both groups concerning age, weight, height, and BMI (Table 1). Statistical analysis revealed that there was a significant difference regarding subject effect $(\mathrm{F}=250.88, \mathrm{p}=0.0001)$ and treatment*time effect $(\mathrm{F}=85.035, \mathrm{p}=0.0001)$ as well as there were significant between subject effect $(\mathrm{F}=1.334, \mathrm{p}=0.0001)$. Multiple pairwise comparison tests revealed that there was a significant reduction $(\mathrm{p}<0.05)$ in the FSH and LH post treatment condition compared with the pre-treatment in both groups. Regarding subject effect, multiple pairwise comparisons revealed that there was a significant reduction $(\mathrm{p}<0.05)$ in the FSH and LH in group A compared with group B at the post 8 weeks of treatment (Table 2). Wilcoxon Signed Rank tests revealed significant reduction in the severity of hot flushes post treatment condition compared with the pre-treatment in both groups. Regarding subject effect, Mann- 
Table 1. Physical characteristics of postmenopausal females with hot flashes in both groups

\begin{tabular}{lccc}
\hline Characteristic & $\begin{array}{c}\text { Group A } \\
\text { Mean }( \pm \mathrm{SD})\end{array}$ & $\begin{array}{c}\text { Group B } \\
\text { Mean }( \pm \mathrm{SD})\end{array}$ & p-value \\
\hline Age $($ years $)$ & $51.35 \pm 2.16$ & $51.25 \pm 2.22$ & 0.886 \\
Height $(\mathrm{m})$ & $1.62 \pm 0.08$ & $1.61 \pm 0.10$ & 0.489 \\
Weight $(\mathrm{kg})$ & $83.05 \pm 8.29$ & $80.95 \pm 10.60$ & 0.582 \\
BMI $\left(\mathrm{kg} / \mathrm{m}^{2}\right)$ & $31.25 \pm 0.46$ & $31.07 \pm 0.55$ & 0.257 \\
\hline
\end{tabular}

Table 2. Descriptive statistic for FSH and LH in postmenopausal females with hot flashes in pre and post 8 weeks of exercises for both groups

\begin{tabular}{lcccc}
\hline \multirow{2}{*}{ Dependent variables } & \multicolumn{2}{c}{ Group A $(\mathrm{N}=24)$} & \multicolumn{2}{c}{ Group B $(\mathrm{N}=24)$} \\
& Pre treatment & Post treatment & Pre treatment & Post treatment \\
\hline FSH & $66.34 \pm 7.69$ & $62.74 \pm 7.81^{*}$ & $66.10 \pm 6.67$ & $59.04 \pm 7.6^{*} \Omega$ \\
LH & $39.37 \pm 4.03$ & $35.83 \pm 4.22^{*}$ & $40.65 \pm 5.15$ & $39.35 \pm 5.24^{*} \Omega$ \\
\hline
\end{tabular}

*Significant $(\mathrm{p}<0.05)$ difference between pre and post treatment, $\Omega$ significant $(\mathrm{p}<0.05)$ difference between both groups at post treatment.

Table 3. Frequency distribution of the hot flushes dairy card in postmenopausal females with hot flashes in pre and post 8 weeks of exercises for both groups

\begin{tabular}{|c|c|c|c|c|c|c|c|c|}
\hline \multirow{2}{*}{$\begin{array}{l}\text { Hot flushes dairy card } \\
\text { Frequency distribution }\end{array}$} & \multicolumn{4}{|c|}{ Group A } & \multicolumn{4}{|c|}{ Group B } \\
\hline & None & Mild & Moderate & Sever & None & Mild & Moderate & Sever \\
\hline Pre treatment* & $0(0 \%)$ & $7(29 . \%)$ & $7(29 \%)$ & $10(42 \%)$ & $0(0 \%)$ & $5(21 \%)$ & $8(33 \%)$ & $11(46 \%)$ \\
\hline Post treatment $\Omega$ & $10(42 \%)$ & $11(46 \%)$ & $3(13 \%)$ & $0(0 \%)$ & $4(17 \%)$ & $9(37 \%)$ & $10(42 \%)$ & $1(4 \%)$ \\
\hline
\end{tabular}

*Significant $(\mathrm{p}<0.05)$ difference between pre and post treatment, $\Omega$ significant $(\mathrm{p}<0.05)$ difference between both groups at post treatment.

Whitney $U$ test revealed that there was a significant reduction $(\mathrm{p}<0.05)$ in the severity of hot flushes in group A compared with group B at the post 8 weeks of treatment (Table 3).

\section{DISCUSSION}

Hot flushes and night sweats are the main physical signs reported by postmenopausal women which affect the psychological state of females and make difficulties of managing them during day-to-day activities ${ }^{15}$. The main cause is the decline in oestrogen concentrations, leading to instability of the hypothalamic production ${ }^{16)}$. At menopause the ovary stops to produce the ova and there is no secretion of estrogen and progesterone, the pituitary gland secretes more FSH and LH to stimulate the ovary, which consider as one of causes of hot flushes ${ }^{3)}$.

In present study, the results showed significant reduction in FSH, LH and improvement of hot flashes dairy card in both groups after treatment in relation to before treatment values and statistically significant lower values of FSH, LH and hot flushes daily card at group A after treatment in comparison to group B. This study results came in accordance with Moilanen et al. ${ }^{17)}$, who examined the impact of aerobic exercises on 176 post-menopausal women with hot flushes, anxiety, and changes in mood. Aerobic activity for 6 months showed improvement in menopausal symptoms. The superior improvements that were recorded in the aerobic exercise group may be attributable to the exercise increase hypothalamic $\beta$-endorphin production, which play role in normalize thermoregulation which disturbed during menopausal hot flushes ${ }^{18)}$. Also, the exercises were preferred by many women as a natural method without side effects ${ }^{1)}$. Elavsky et al. ${ }^{19)}$ stated that regular and long-term aerobic training improve the vasomotor symptoms and physical fitness. Also, Fox ${ }^{20)}$ has shown that active individuals have higher basal levels of $\beta$-endorphins than those who with sedentary life because; exercise may stabilize the thermoregulatory center and decrease the risk of hot flushes, also exercise improve mental health outcomes by providing a distraction or decrease anxiety and enhance psychological feeling. In addition, there is evidence that as increase level of endorphins, the frequency and amplitude of LH hormone decreases, which regulate gonadotropin releasing hormone levels ${ }^{21)}$. Furthermore, aerobic training has the potential to increase serotonin in the brain ${ }^{22)}$. Serotonin is an important neurotransmitter for emotional correction ${ }^{23)}$. The results agree with Mohamed et al. ${ }^{12)}$, who stated that regular aerobic exercise assisted with soy products appears is an effective, safe and successful alternative method to decrease hot flushes and improves quality of life in postmenopausal women. Despite the intergroup superior effect of aerobic exercises, the laser acupuncture group also exhibited significant intragroup improvements. These improvements are attributable to acupuncture stimulate and release neurochemicals, such as $\beta$ endorphins, enkephalins, and serotonin Thus, it is central to the production and treatment 
mania-depression, dysthymia, obsessive compulsive disorder, pre-menstrual syndrome and anorexia ${ }^{24)}$. Also, acupuncture alters the opioidergic neurotransmission activity in the brainstem, thalamus, hypothalamus, and/or pituitary ${ }^{25)}$. Moreover, acupunctures regulate the autonomic nervous system. According to the site of stimulation, acupuncture can alter sympathetic and parasympathetic nervous system response ${ }^{26)}$. The results agree with Elshamy ${ }^{27)}$ who concluded that that laser acupoints are effective and can be used as an alternative treatment to decrease the frequency and severity of postmenopausal hot flushes. The findings of the study may be limited by psycho physiological and cultural issues and the the lack of follow-up for postmenopausal hot flushes in both groups for several months' after rehabilitation program to evaluate the long lasting effect. In conclusion this study shows that a 8-week program of an aerobic exercises yields improvement in FSH, $\mathrm{LH}$, and decrease in severity of hot flushes assessed by hot flush dairy card than laser acupuncture in the treatment of postmenopausal hot flashes.

\section{Conflict of interest}

None.

\section{REFERENCES}

1) Chattha R, Raghuram N, Venkatram $P$, et al.: Treating the climacteric symptoms in Indian women with an integrated approach to yoga therapy: a randomized control study. Menopause, 2008, 15: 862-870. [Medline] [CrossRef]

2) Greer A, Germaine B: The change: women, aging, and menopause, 1st ed. New York: Alfred A. Knopf, 2000, pp 32-35.

3) Boryensko, Joan A: Woman's book of life: the biology, psychology, and spirituality of the feminine life cycle, 2nd ed. New York: Riverhead Books, 2005, pp $1100-1110$.

4) Sallam H, Galal AF, Rashed A: Menopause in Egypt: past and present perspectives. Climacteric, 2006, 9: 421-429. [Medline] [CrossRef]

5) Gambacciani M, Pepe A: Vasomotor symptoms and cardiovascular risk. Climacteric, 2009, 12: 32-35. [Medline] [CrossRef]

6) Daley A, MacArthur C, McManus R, et al.: Factors associated with the use of complementary medicine and non-pharmacological interventions in symptomatic menopausal women. Climacteric, 2006, 9: 336-346. [Medline] [CrossRef]

7) Nedrow A, Miller J, Walker M, et al.: Complementary and alternative therapies for the management of menopause-related symptoms: a systematic evidence review. Arch Intern Med, 2006, 166: 1453-1465. [Medline] [CrossRef]

8) Conn VS, Hafdahl AR, Porock DC, et al.: A meta-analysis of exercise interventions among people treated for cancer. Support Care Cancer, 2006, 14: 699-712. [Medline] [CrossRef]

9) Schmitz KH, Holtzman J, Courneya KS, et al: Controlled physical activity trials in cancer survivors: a systematic review and meta-analysis. Cancer Epidemiol Biomarkers Prev, 14: 1588, 2005-1595.

10) Hu WL, Chang CH, Hung YC, et al.: Laser acupuncture therapy in patients with treatment-resistant temporomandibular disorders. PLoS One, 2014, 9: e110528. [Medline] [CrossRef]

11) Whittaker P: Laser acupuncture: past, present, and future. Lasers Med Sci, 2004, 19: 69-80. [Medline] [CrossRef]

12) Mohamed M, Mohamed G, Abou-Louz S: Effect of aerobic exercise assisted with soy products on hot flushes and quality of life in postmenopausal women Bull Fac Phys Ther, 2015, 20: 1-9.

13) Zhou J, Qu F, Sang X, et al: Acupuncture and auricular acupressure in relieving menopausal hot flushes of bilaterally ovariectomized Chinese women: a randomized controlled trial. Evid Based Complement Alternat Med, 2011; 2011: 713274.

14) Avis NE, Stellato R, Crawford S, et al.: Is there a menopausal syndrome? Menopausal status and symptoms across racial/ethnic groups. Soc Sci Med, 2001, 52: 345-356. [Medline] [CrossRef]

15) Hunter MS, Gentry-Maharaj A, Ryan A, et al.: Prevalence, frequency and problem rating of hot flushes persist in older postmenopausal women: impact of age, body mass index, hysterectomy, hormone therapy use, lifestyle and mood in a cross-sectional cohort study of 10,418 British women aged 54-65. BJOG, 2012, 119: 40-50. [Medline] [CrossRef]

16) Gold EB, Sternfeld B, Kelsey JL, et al.: Relation of demographic and lifestyle factors to symptoms in a multi-racial/ethnic population of women 40-55 years of age. Am J Epidemiol, 2000, 152: 463-473. [Medline] [CrossRef]

17) Moilanen JM, Mikkola TS, Raitanen JA, et al.: Effect of aerobic training on menopausal symptoms-a randomized controlled trial. Menopause, 2012, 19: 691-696. [Medline] [CrossRef]

18) Luoto R, Moilanen J, Heinonen R, et al.: Effect of aerobic training on hot flushes and quality of life — a randomized controlled trial. Ann Med, 2012, 44: 616-626. [Medline] [CrossRef]

19) Elavsky S, McAuley E: Physical activity and mental health outcomes during menopause: a randomized controlled trial. Ann Behav Med, 2007, 33: 132-142. [Medline] [CrossRef]

20) Fox KR: Self-esteem, self-perceptions and exercise. Int J Sport Psychol, 2000, 31: 28-40.

21) Daley AJ, Stokes-Lampard H, Thomas A, et al.: Aerobic exercise as a treatment for vasomotor menopausal symptoms: randomised controlled trial protocol. Maturitas, 2013, 76: 350-356. [Medline] [CrossRef]

22) Patrick RP, Ames BN: Vitamin D and the omega-3 fatty acids control serotonin synthesis and action, part 2: relevance for ADHD, bipolar disorder, schizophrenia, and impulsive behavior. FASEB J, 2015, 29: 2207-2222 [CrossRef]. [Medline]

23) Harmer CJ: Serotonin and emotional processing: does it help explain antidepressant drug action? Neuropharmacology, 2008, 55: 1023-1028. [Medline] [CrossRef]

24) Berman BM, Langevin HM, Witt CM, et al.: Acupuncture for chronic low back pain. N Engl J Med, 2010, 363: 454-461. [Medline] [CrossRef]

25) Lin JG, Chen WL: Acupuncture analgesia: a review of its mechanisms of actions. Am J Chin Med, 2008, 36: 635-645. [Medline] [CrossRef]

26) Cabioglu MT, Ergene N, Tan U: Smoking cessation after acupuncture treatment. Int J Neurosci, 2007, 117: 571-578. [Medline] [CrossRef]

27) Elshamy F: Effect of laser acupoints on postmenopausal hot flushes. IJSR, 2014, 3: 1040-1043. 